\title{
Listening in a Second Language: Hermeneutics and Inner Speech
}

\author{
John M. Murphy
}

\begin{abstract}
The purpose of this article is to broaden the current theoretical basis for describing listening as a dynamically interpretive language process by reviewing two areas in the literatures on comprehension and interpretation that generally are not cited by writers interested in the listening process. These complementary theoretical traditions lend support to the more familiar characterizations of listening as an active language process that have emerged from the basic tenets of cognitive science. Within the cognitive framework it is widely acknowledged that listeners engage in the use of deliberate, as well as automa-
\end{abstract}

\begin{abstract}
tic, strategies for listening. By introducing less familiar themes that actually reinforce cognitive descriptions, it is hoped that the research literature into the second language (L2) listening process will be enriched. The philosophical tradition of 'hermeneutics', and a description of internal mental processes known as 'inner speech', are two specific areas of the literature that are discussed. Following an explication of the underlying processes that underpin these theoretical traditions, a pedagogical model is proposed for the teaching of academic listening skills in the L2 classroom.
\end{abstract}

Listening comprehension is increasingly being described as an active and interpretive language process in which listeners are dynamically engaged in the construction of meaning. While attending to spoken language, listeners are said to do more than passively sample incoming messages but, more critically, are characterized as actively involved in predicting topic developments, using a series of definable strategies for listening, and relating what they hear to their personal stores of prior knowledge (O'Malley, Chamot, \& Kupper, 1987; Murphy, 1987; Dunkel, 1986; Nagle \& Sanders, 1986; Wipf, 1984; Crow, 1983; and Goss, 1982). This theoretical view of the listening process emerges from the general framework of cognitive science and, over the past 15 years, has been influenced greatly by research into the reading process. Such a description of listening sometimes seems to contradict many commonly held assumptions concerning aural comprehension. Perhaps due in part to the structuralist / behaviourist descriptions of language comprehension prevalent during the 1950s and 1960s, we continue to encounter teacher trainees and some second language (L2) practitioners who are inclined to think of listening as a passive skill. In addition, many teachers of second languages who accept the description of listening as an active language process have yet to integrate this view into their classroom curricula. The purpose of 
the present article is to strengthen our theoretical basis for describing listening as an active language process while reaching beyond the more familiar themes from cognitive science. By demonstrating that there are other theoretical traditions that support an active view of listening as outlined above, it is hoped that the research literature into the listening process will be broadened and enriched. The philosophical tradition of hermeneutics and psychological analyses of inner speech are two less familiar areas of the literature that are worthy of closer examination.

\section{Hermeneutics}

Hermeneutics, a term that literally means the art of interpretation, has come to play a central role within a variety of disciplines that deal with the process of developing understanding. As the root of the term reflects, one of the responsibilities of the Greek god Hermes was to assist mortal men as they struggled to understand the words of the gods. From these historical origins, philosophical hermeneutics has grown to focus on the interpretation of sacred, legal, and more recently, literary texts. As it is developing in the philosophical tradition of Heidegger, Gadamer, Ricoeur, and Habermas, hermeneutics is based on the premise that an interpreter does not recreate an objectifiable meaning originally created by an author, but that the interpreter joins the author in the creation of meaning. More simply stated, messages may be presented by speakers, writers, or artists but it is through a process of hermeneutic interpretation that actual meanings enter into the worlds of the perceivers.

How might a hermeneutic examination of the listening process be linked to theory and practice in the teaching of second languages? One connection is rooted in hermeneutics' fundamental concern with developing understanding, a goal shared by second language teachers and researchers. Ochsner (1979) convincingly has argued that hermeneutics could begin to play a central role in the development of theory and research methodology in the field of second language acquisition (SLA). The emergence of diary studies as a viable method for research in SLA attests to a growing acceptance of Ochsner's thesis. In one of the better known investigations of this kind, Bailey (1983) reminds us that familiarity with the traditions of both empirical science and hermeneutics can provide researchers with tools necessary to examine processes involved in SLA from these two complementary perspectives. Because one of the aims of diary studies is to better understand SLA through introspection and self-reflection while the learner is engaged in the process of learning a second language, Bailey describes this research methodology as emerging from the tradition of hermeneutic science. For the purposes of this brief introduction, discussion will be restricted to the connection between hermeneutics and the process of listening in a second language. 
In an essay that places the discipline of first language (L1) speech communication firmly within this tradition, Stewart (1983) describes four major themes of modern day hermeneutic science. An understanding of these themes will facilitate a philosophically based perspective on the listening process. These four themes are: openness, linguisticality, play, and fusion of horizons. Meanings are said to be open in the sense that an interpreter participates in the development of understandings as language is encountered. Speakers do not explain things that are simply comprehended directly by listeners. It is while interacting with speakers that listeners are viewed as cooperating in the creation of meaning. The messages that emerge through interactions between speakers and listeners are contingent upon situational, historical, cultural, and linguistic contexts. Brown (1987) in her review of the past twenty-five years in the teaching of L2 listening comprehension makes the point that all language is inferred from and understood in context. The hermeneutic emphasis upon openness supports this position. It affirms that within the realms of all human knowledge (science, history, literature, music, law, etc.) all understandings are inherently contextual and historically situated. We cannot separate the perceiver from the act of perceiving, nor from the product of what is perceived. Furthermore, hermeneutics proposes that all human understandings are necessarily provisional, tentative, and open to present and future change. What we comprehend is not a product of a static or closed system, but is open to continuing development and modification. Truthfulness, accuracy, or correctness are not what is fundamentally at issue, what occurs during listening is the co-construction of messages between people. Listeners and speakers are participating in a cooperative process of determining meanings. In the hermeneutic tradition, the subjectivity of the perceiver is recognized as an integral aspect of the listening process.

The emphasis upon linguisticality is a recognition that all human experience is permeated by oral and written language. From this perspective our linguistic systems are not described as representing the worlds of experience, but as disclosing them. Learning to comprehend and speak does not mean learning to use pre-existing tools for interacting with a world outside one's self, rather the acquisition of these abilities is coupled with the acquisition of increased, or more complete, knowledge of the world. Along these lines, Palmer (1969) characterizes language as a medium for experiencing, thinking, understanding, and existing as a human being. One rapidly emerging theme in the literature on teaching second languages is the central role to be played by the integration of content-area instruction into curriculum design and methodological approach (Chamot \& O'Malley, 1987). A "cognitive academic language learning approach" as described by Chamot \& O'Malley or an "integrative language development approach" as described by Milk (1985) are consonant with this aspect of 
the hermeneutic tradition. In the teaching of English as a second language (ESL) we would expect second language learners' continuing acquisitions of listening proficiency to emerge hand in hand with their mastery of new concepts, vocabulary, and skills from content-areas such as science, mathematics, history, geography, language arts, physical education, movement science, health science, culinary arts, industrial arts, literature, et cetera. For example, ESL children may be guided into the mastery of concepts from geography while interacting on meaningful and communicative levels with other ESL, or native speaker, classmates. Together, students may go about the task of constructing maps, examining distances, or some related activities that require mutual exchanges of information. As they learn cooperatively, L2 students will be expanding their control over the new linguistic system, in addition to learning about geography, in order to get these jobs done. Research into the potential value of language exchanged during periods of teacher-structured, student-to-student, peer activities supports the findings that language-practice opportunities are increased, the quality of student talk improves, positive affective climates are promoted, and ESL learners manifest increased motivation to learn (Long \& Porter, 1985). This is the sense in which ESL methodologies centred upon content-area instruction may be linked to the hermeneutic concept of linguisticality. Our language systems serve as a medium for disclosing the world around us.

In the third theme from hermeneutics, language is seen as a form of play between speakers and listeners. This analysis is especially germane to the discussion of L2 listening in non-formal settings (e.g., conversations, group work activities). Partners in conversation enter into a dynamic interaction in the same way as one might begin to play a game of tennis. There are previously established rules but no one knows exactly how the game will develop nor what the specific outcomes will be. Uncertainty is part of the game and the resolution of uncertainty is one of the reasons for playing. Speakers typically do not present to their listeners messages that are tightly planned and immutable but commonly adapt what they say to the contexts; and these contexts are ever changing. Both spontaneous conversation and academic discourse are made up of a give and take that generates surprises and insights. For example, the way topics are selected for discussion and the strategies people implement in order to introduce, develop, modify, or change them constitute important dimensions of interpersonal communication (Richards, 1980). Once some topics have been introduced they are immediately agreed upon and developed by all parties involved. Other topics are inserted unexpectedly into the midst of a conversation that was already in progress. Sometimes a speaker may introduce a topic that ends up being completely ignored by the other participants in the conversation. An example of subtle shifts in topic selection and 
development is captured in this excerpt from a transcript of an academic lecture entitled An Introduction to Basic Marketing, presented by Ruetten (1986, pg. 90).

Teacher: ... someone might have preferred the shoe to look a little different or might have preferred it to be located a little closer to their home but if exchange takes place then these utilities were present in an adequate amount, all right now this ...

Student: I have a question. (an unexpected interruption)

Teacher: Okay, Les.

Student: What types of restrictions are placed on various kinds, various types of department stores, by that I mean can any type of department store get a certain type of shoe made by a manufacturer? (a topic shift, unplanned)

Teacher: No, no they can't.

Student: So that would be a barrier that would be a possession barrier. (synthesizing material in an unexpected way)

Teacher: That would be a possession barrier, that's correct, if a manufacturer does what we call selective distribution and only allows his shoes to be carried in stores of a certain type then that would be a barrier to possession utility that . . .

Student: So that's a barrier the consumer can do nothing about that at all. (another topic shift)

Teacher: Well, yes he can. You see because presumably that's not the only store in town and generally the selective distribution guarantees certain stores in each shopping area will carry the product so if he couldn't get it at that department store but he could get it at another . . okay, so let's talk for a few minutes now about the, about how these utilities are created. (The student generated topic has been addressed, teacher returns to planned structure for the lecture.)

All of the participants in an interaction potentially may affect the messages in the process of being shared between them. It is within this playful interaction that the rules of the game are established, followed, shattered, and reborn. Unlike a game of tennis, speakers and listeners have no referee to stop them when they are bending or breaking the rules, just about everything is open to negotiation. Some aspects of the game are being reinvented with every interaction. "The conversational partners enter a dynamic over which they do not have complete control, and the outcome of their talk can be a surprise to both of them, a creation of their meeting" (Stewart, 1983, pg. 387). Conversations begin to take on a life of their own for just as the participants are playing a game, they are also being played by it.

Perhaps the most powerful image from hermeneutics that can be related to understanding and listening is what Gadamer (1976) and Ricoeur (1981) 
refer to as the fusion of horizons. In this analysis, messages are said to be comprehended through a meeting of two or more people's horizons. Though it carries definite implications for more formal settings as well, this image is particularly striking in the context of conversational, face-toface communication. Gadamer describes one's horizon as the range of vision embracing everything that can be seen from a particular vantage point. The horizon is the totality of one's awareness of the world. It includes the listener's background knowledge, prejudices, emotional states, ambitions, fears, assumptions, personal history and everything that defines him or her as an individual. Not only is the horizon carried along by the listener but it is fluid and changes as one comes into contact with the horizons of others. It is something into which listeners move as they interact with speakers; something listeners carry along with them; and something that accompanies all parties involved in the process of communication.

When two people meet during the process of developing understandings there is a potential for joining together some areas of their horizons. Since horizons are fluid they are in constant flux and are subject to change. Stewart (1983) emphasizes the tentative nature of the fusion of horizons:

Although with understanding the interpreter's horizon expands to include the horizon of the text or the other, the term fusion does not mean that the horizons are reconciled. Differences still remain, and one critical aspect of hermeneutic consciousness is acceptance and even celebration of the 'tension' between irreconcilable horizons. (pg. 388)

When examined from the perspective of the fusion of horizons, listening emerges as an interactive process of negotiation between two or more participants in communication. This interactive process begins with the differences between speakers and listeners and culminates with two (or more) people subjectively constructing understandings between them. From these four themes of hermeneutics (openness, linguisticality, play, and fusion of horizons) we see that there is a philosophical rationale for describing listening as a dynamically interactive and creative process.

\section{Inner Speech}

A second topic to be explored in order to gain a better grasp of what listening entails is that of inner speech. This concept derives from the work of the Russian psychologists Vygotsky (1962), Luria (1969), and Sokolov (1972) and recently has been re-introduced into the literature on L1 speech communication by Streff (1984) and Johnson (1984). These theorists point out that when we listen to others we do so through a medium they call inner speech. The role played by inner speech may be 
seen as central to the listening process for it is defined as the way in which people communicate intrapersonally (i.e., within their own minds). As a vehicle for intrapersonal communication inner speech has been characterized by (1) highly egocentric messages, (2) restricted levels of semantic elaboration, (3) restricted levels of syntactic elaboration, and (4) silence from the perspective of an outsider. In this analysis listening can be defined as an inner speech behaviour involving the transformation of words and ideas produced by others into conceptual thoughts within the individual listener (Johnson, 1984). Examining the listening process in this way reveals complex relationships between spoken language as it is produced in the external world, and how messages come to be internalized within the inner world of the listener.

One problem associated with the study and analysis of inner speech relates to research methodology. We have ways to investigate external speech by means of discourse analysis, for example, but how does one begin to delve into the less accessible realm of internal thought processes? The seminal studies conducted by Vygotsky, and the ones which have a direct impact upon this essay, were centred upon the analysis of spoken language used by young children. Echoing the conclusions of Piaget (1955), Vygotsky's work with children led him to describe the egocentric, non-elaborated characteristics of their speech. Johnson (1984) elaborates:

One of the major conceptual differences between Piagetian and Vygotskian developmental schemas rests with the outcome of egocentric speech. Piaget claimed it disappears as a result of cognitive development, whereas Vygotsky asserted that it transforms itself into inner speech to serve a cognitive function. (pg. 212).

Vygotsky's position is that inner speech initially emerges in the child's early use of egocentric spoken language and that as children gain experience they learn to become more explicit in their control over extrapersonal language forms. Eventually the compressed forms of egocentric language are turned inward and become the primary mode for intrapersonal thought. In Vygotsky's analysis the egocentric spoken language of the child is seen as a precursor of inner speech and functions as the medium for its genesis.

In another method for investigating inner speech reviewed by Sokolov (1972) mature participants are introduced to techniques for reporting their introspective thought processes. After being trained to combine introspection with self-reporting, subjects are directed to orally unravel the meanings of aphorisms or paradoxical statements, and what they say is examined for glimpses it might provide into the inner workings of the thinking process. For example, a subject might be asked if he can explain his understanding of an utterance such as: Alice asked how the apple got to be on the tree, and in the meantime somebody else had silently removed 
it. Using research methodologies that combined introspection, self-reporting, and observation, researchers in this tradition came to the conclusion that the flow and movement of thought is not reflected directly and immediately with the expression of external speech. "That which is contained in thought simultaneously, is developed in speech successively . . . (thinking) might be compared to an overhanging cloud pouring out in a rain of words," (Vygotsky, as cited by Sokolov, 1972: pg. 47).

As defined in this school of Russian psychology, inner speech is characteristically dissimilar to spoken language. It is different in relation to audience orientation, semantic load, and syntactic structure. These attributes of inner speech make it well suited for the purposes of intrapersonal thinking and planning. Because it carries high degrees of ellipsis and syntactically reduced forms, inner speech is usually described as being condensed and compact. Vygotsky states:

Inner speech is not the interior aspect of external speech-it is a function in itself . . . while in external speech thought is embodied in words, in inner speech words die as they bring forth thought. Inner speech is to a large extent thinking in pure meanings. It is a dynamic, shifting, unstable thing, fluttering between word and thought, the two more or less stable . . . components of verbal thought . . (pg. 149)

Within inner speech individual words can be loaded with connotative meanings that would take more precise embellishment and a greater volume of language to explain if one were speaking extrapersonally. Vygotsky maintains that "a single word is so saturated with sense that many words would be required to explain it in external speech." "No wonder", he continues, "that egocentric speech is incomprehensible to others . . . between people in close psychological contact (e.g., spouses, siblings, or best friends) words acquire meanings understood only by the initiated. In inner speech, the same kind of idiom develops . .." (pg. 148). In order to transfer a thought from inner speech to an extrapersonal communication one would have to elaborate extensively on the levels of semantics and syntax. Luria (1969) refers to this when he remarks:

Because it is 'speech for oneself,' serving above all to fix and regulate intellectual processes, ... inner speech necessarily ceases to be detailed and grammatical. It contracts, acquiring a folded, grammatical structure, preserving, however, the possibility of developing into a complete, differentiated and complex utterance. (pg. 121-162)

When listening, the tendency may be to reduce the elaborated language one hears to a compressed inner speech core, and to prune out message information that is not central to the gist of what the listener perceives the speaker to be saying. 
In Thought and Language, Vygotsky (1962) notes that within the process of extrapersonal communication there is a dynamic relationship between one's internal thoughts and the language used to express them. As speakers, we do more than merely externalize the thoughts we carry around in our heads through an external medium called speech, rather, there is a "continual movement back and forth from thought to word and from word to thought" (pg. 125). Within this context Johnson (1984) proposes a similar connection between the processes of listening, speaking, and thinking by suggesting that all three are interrelated in a helical system of intrapersonal to extrapersonal communication. To be more explicit, listening may be described as one subset of the broader realm of intrapersonal thinking. Inner speech may serve as a dual purpose medium for generating one's original thoughts (thinking) and for figuring out what other people have intended to say (listening). Both roles of inner speech are connected in a complementary process of exchange, and it is from these undisclosed channels of intrapersonal communication that the products of one's listening emerge.

From these frames of reference, inner speech as compared with extrapersonal speech, we learn that different settings for communication will make varying demands upon listeners as they interpret what they hear. For a casual conversation in which two people are speaking about uncomplicated or context-explicit topics, the non-elaborated nature of inner speech poses no problems. Casual communication presents little trouble as long as the participants are moderately proficient in the language being used. When topics become more challenging and the relationship between the participants becomes more formal, as in the cases of business meetings, academic debates, or classroom seminars, listening becomes more taxing. In these settings inner speech is being challenged to cope with elaborated messages that carry a higher density of information content and that make references to contexts that are less immediately available. Vygotsky has proposed the concepts of displacing and decentering in order to illustrate some of the mental activities that are called into play as these greater demands are made upon the listener.

It is sometimes necessary for a listener to decenter and/or displace to a speaker's perspective in order for effective communication to take place. These may be critically important abilities within the listening process. Decentering refers to the attempt to understand messages impartially or from another's point of view. It is an ability that jurors are expected to exercise in the courtroom by lawyers who present evidence supporting their respective clients' interpretations of events. Decentering is often defined as the opposite of egocentrism or the degree to which we tend to see the world restrictively through our own personal frames of reference (Piaget, 1955). The ability to decenter indicates that one is flexible enough 
to temporarily try and take on another's perspective, to get outside one's self. It entails the attempt to see the world as others see it.

The attempt to decenter as one tries to take on the perspective of another might seem familiar to ESL teachers who are acquainted with the L2 methodology known as Counseling-Learning/Community Language Learning (CL/CLL) (Rardin \& Oprandy, 1985; Stevick, 1980; Curran, 1978, 1976, 1972). In fact CL/CLL is one L2 methodology that permits teachers and students recurring opportunities to explore each others' points of view, and can be adapted in order to practice strategies for decentering as defined by Vygotsky. As a starting point that is useful during conventional, whole-group, classroom lectures, teachers periodically might interrupt themselves long enough to provide opportunities for members of the class to paraphrase or summarize the content covered up to that point in the lecture. This can be done as a whole group activity, or can be conducted as a peer-to-peer interaction. When listeners are afforded intermittent opportunities to paraphrase they are reported to demonstrate a deeper level of engagement and better comprehension of the material presented (Glynn \& Hartzell, 1978; Ross \& Divesta, 1976; Allison, 1971). During such activities, student listeners can be encouraged to seek to understand the speaker's message from the speaker's point of view rather than from their own. When implementing this procedure, teachers can incorporate lessons they learn while listening to students' paraphrasing attempts into the subsequent sections of their developing lectures. This would be a useful technique because it affords speakers opportunities for decentering to the perspectives of their listeners. To analyze their audience in preparation for oral presentations, students can be encouraged to practice decentering techniques by taking into consideration the potentially different points of view of their classmates.

Displacement refers to the capacity for using the imagination to transcend time and space while attending to language. For example, we exercise the ability to displace when listening to a radio broadcast of a theatrical event. Perhaps the drama is taking place aboard a ship, in a bar, on death row, or in the living room of an unfamiliar culture. As radio listeners recreate in their own minds what the sets, props, costumes, faces, gestures, and smells might be like they are imaginatively displacing themselves in time and place. People who share some of the excitement of space travel by imagining what it must be like to view the planet Earth from far above its surface, while their feet are planted firmly upon the ground, know the experience of displacing. Displacing and decentering are examples of the kinds of abilities ESL students, and especially ESL university students, will need to cultivate and master if they are to function effectively as listeners in academic settings. 


\section{Implications}

The preceding review offers some points of departure for a consideration of the literature on listening. When examined through the perspective of hermeneutic science the listening process begins to take on a theoretical basis that is somewhat unsettling as it differs from the kind of descriptions traditionally proposed. Listening is often handled in L2 classrooms as if there are specifiable interpretations of listening selections that can be comprehended, or ought to be comprehended, in specific ways. This may be why so much of the literature on listening is concerned with establishing measurements of accurate listening. With some notable exceptions (Brown, 1987; Dunkel, 1986; Mendelsohn, 1984), we seem to be less interested in developing a clearly articulated theoretical foundation for what the listening process entails, and for teaching to that process, than with creating listening tests. A traditional concern with the measurement of listening is pointed out by Rubin \& Roberts (1987):

Though the bulk of the current academic research effort seems to be concentrated on measurement rather than on development of listening theory, it would seem more prudent to discover what it is that we should be studying before deciding how we should measure it (pg. 142)

One investigator of second language acquisition has succinctly expressed this dilemma by pointing out that in the field of L2 instruction teachers have become better at testing listening comprehension than in developing students' listening abilities through a clear understanding of underlying processes (Matthews, 1982).

The objective of the present article has been to review some less common areas of the literature on listening at the level of theory building. The hermeneutic position can be expressed concisely in the following way: to interpret an event is fundamentally a personal act (Ochsner, 1979). Along these lines we recently have started to emphasize the roles played by prior knowledge and schemata in the comprehension process (Carrell, 1984). The products of one's listening are determined to a large extent by the information one contributes to the task of comprehending. Listening is part of a larger hermeneutic process in which speakers and listeners meet and collectively create meanings. Listening permeates our interactions with those around us as we gain experience in the give and take of interpersonal communication while learning more about the world in which we live. The products of listening are not pre-set or pre-determined but are contingent upon the commonly unexpected contributions of everyone engaged in any particular listening event.

The literature on the teaching of listening to ESL students demonstrates 
a clear concern with early and intermediate levels of second language acquisition. In the L2 literature there has not been as much emphasis on what to do in relation to listening instruction at more advanced stages of language proficiency. For more proficient L2 learners, ESL teachers could turn to the literature on speech communication which addresses the needs of native language speakers (Wolff, Marsnik, Tacey, \& Nicholes, 1983; Wolfin \& Coakley, 1982). When this is done, one finds that fluent L1 speakers are in need of listening for specific purposes (e.g., to empathize, to evaluate, to enjoy, to analyze, to critique, and to take written notes), especially as they prepare to become university students.

Applying the theories of inner speech to the process of listening in a second language is useful because these provide us with some explanations for what teachers find happening in their classes. When listening in a lecture setting, for example, a student is attending to highly elaborated extrapersonal speech. Listeners inevitably will bring the elaborated messages they hear down into the realm of non-elaborated inner speech as part of their efforts to make sense of what is being explained. Language teachers should be aware that when they ask ESL listeners to recollect the many details of elaborated speech, they may be working against the students' natural tendencies for semantic and syntactic reduction. Listening is a language process in which messages are interpreted rapidly, and these interpretations tend not to be elaborate and explicit. Even proficient listeners are not very effective at coping with messages that are heavily loaded with detailed information.

Through instruction that aims to enhance some of the abilities discussed within the frameworks of hermeneutics and inner speech, language learners may learn to work realistically within the listening process. In an academic setting this experience may encourage them to see the needs for attentiveness, imaginative engagement, self-confidence, and peer collaboration while preparing to make sense of highly elaborate messages. They will learn to take advantage of the individual stores of information, experience, and self-composure they may contribute to the listening experience. Listeners will gain practice in working with the streamlining nature of their channels for intrapersonal thinking in order to embrace more of what is central to the messages being presented. They will learn to listen judiciously for major concepts, higher level themes, and important pieces of information while screening out matters that are less critical to the gist of the content being expressed. This will take some effort, and explains why students tire easily when listening to material that is challenging. Listening to academic lectures for the purposes of comprehension, notetaking, and discussion is one area of preparation for university-level studies that applies to all student populations. ESL students may have a more obvious need for instruction of this kind, but few students reach the university-level 
ready to cope with the challenge of listening effectively to academic lectures. There are a number of commercially available materials that provide excellent resources for teachers who plan to introduce ESL students to the demands of academic listening (Lebauer, 1988; Ruetten, 1986; Mason, 1983; Dunkel \& Pialorsi, 1982; Young \& Fitzgerald, 1982; Sims \& Peterson, 1981; Kisslinger \& Rost, 1980). All of these materials include a series of fully developed academic lecture selections that are designed to be used with ESL students who are enrolled in a university-level course in academic lecture comprehension. Most of them include practical recommendations on various aspects of the listening process such as how to make use of a lecturer's suprasegmental cues (e.g., intonation contours, stress markers), how to determine the meaning of unfamiliar vocabulary from contextual clues, how to take effective written notes, et cetera. Based upon previous research (Murphy, 1987), and as an additional means for working with listening materials such as the ones mentioned above, the following model of listening strategies (figure 1) may serve as an aid for ESL students while they are learning to make sense of academic lectures. Students and teachers periodically might refer to it in order to develop a better sense of what could be taking place within a student's mind (intrapersonally) while listening in academic settings.

\section{Figure 1. Model for Listening Strategies Used in Academic Settings}

\section{Recalling and Summarizing:}

- What is the general aim of this presentation?

- What is the speaker saying right now?

- Do I need to remember this?

- Is this important enough to write down?

- Have I read about this before? (Is it in my book?)

\section{Speculating:}

- Where is the speaker heading in a general sense? How do I know?

- Can I relate any of this information to something I already know? Is it worth mentioning? Is it worth writing down?

- Do I know of an example that might help the speaker make the topic clearer?

- What will the speaker probably be saying next? How do I know?

- What is the point of this discussion?

\section{Self-Examining:}

- Could I summarize what the speaker is trying to explain?

- Do I have any experience in this area?

- Am I getting most of this? Do I understand it well?

- Is there anything bothering me about this information?

- Am I staying on target with the speaker's topic, or am I drifting off and missing what the speaker means to say? 


\section{Probing the Topic:}

- Is this important information?

- What are the key words being used?

- Which of the concepts being presented are relatively more important?

- Why is the speaker saying ". . . . . ."?

- Do I see any connections between the ideas being presented?

- How does this idea fit into the speaker's overall plan?

- How has this presentation been organized?

\section{Interacting with Others:}

(While aiming to help the speaker make things clearer for myself and others)

- Is this a convenient time for me to speak up in class by:

- summarizing some of the content being explained?

- asking a question?

- providing a new and different example?

- asking for help?

- pointing out a relationship between ideas that some listeners may be missing?

\section{Conclusion}

In addition to instruction in the kinds of strategies for effective listening listed in figure 1, a complementary direction for the classroom is to focus upon a theoretical basis for the listening process that includes a discussion and explication of some of the underlying concepts from cognitive science, hermeneutics, and inner speech that have been mentioned in this paper. Also, we need to provide the means for students to explore the process of listening first-hand. Once an exploration of the process has been initiated students need to be guided in the expansion of their strategies for listening, reviewing, integrating, and studying. Such activities will lead them to develop a more realistic appreciation for the nature of the listening process and can be tied to their development as readers, speakers, and writers.

Along with the recognition that L2 learners need more experience in coping with academic lectures, comes an implication that language teachers need to become comfortable and skilful in making content-area oral presentations in their classes. In other words, teachers need to speak to students on academically challenging topics. Frequent interactive-lecturing for the purposes of global comprehension, notetaking, review, study, and discussion will provide a valuable source of listening activities in the classroom. The content of the topics used need to be tailored to the proficiency and experience levels of the students being addressed, and to their interests, but as much as possible the topics should simulate the kind of lecture material that might be presented in mainstream academic settings. With the return of many universities to core curriculum requirements, the materials commonly included in core courses might best serve these pur- 
poses. This is not to say that ESL classes should become identical in format to regular university classrooms. We need to juxtapose teachercentred lecturing for the purposes of academic listening against the full range of small group, student-centred, and interactive formats currently being discussed in the literature (Bejarano, 1987; Long \& Porter, 1985). But when it is an appropriate time for practice in academic listening, students ought to have access to the live presentation of language (on an appropriate topic) being created in front of their eyes. They need opportunities to ask questions, summarize, elicit contextual clarifications, agree, argue, and demand elaborations for what they consider to be important issues. This kind of realistic, spontaneous, and unpredictable interaction will not be as likely to take place if the lecture is not being presented via the live format. As necessary aids for the lecturer who plans to address effectively the needs of ESL learners, the complementary lenses of cognitive science, hermeneutics, and inner speech should foster a better conceptual understanding of the processes that underpin the listening experience.

\section{REFERENCES}

Allison, T.L. (1971). A comparison of reinforcement activities for listening comprehension. Unpublished doctoral dissertation. Syracuse University. (ERIC Document Reproduction Service No. Ed 074 470).

Bailey, K. (1983). Competitiveness and anxiety in adult second language learning: Looking at and through the diary studies. In H.W. Selinger \& M.H. Long (Eds.) Classroom Oriented Research in Second Language Acquisition. Rowley, Mass.: Newbury House Publishers.

Bejarano, Y. (1987). A cooperative small-group methodology in the language classroom. TESOL Quarterly, 21(3), 483-504.

Brown, Gillian. (1987). Twenty five years of teaching listening comprehension. FORUM, 25(4), 11-15.

Carrell, Patricia L. (1984). The effects of rhetorical organization on ESL readers. TESOL Quarterly, 18(3), 441-469.

Chamot, A.U. \& J.M. O'Malley. (1987). The cognitive academic language learning approach: A bridge to the mainstream. TESOL Quarterly, 21(2), 227-250.

Crow, John T. (1983). Psycholinguistics and listening compehension. Unpublished paper presented at the 1983 National TESOL Convention. Toronto, Canada.

Curran, Charles A. (1978). Understanding: A Necessary Ingredient in Human Belonging. Apple River, Illinois: Apple River Press.

. (1976). Counseling-Learning in Second Languages. Apple River, Illinois: Apple River Press.

(1972). Counseling-Learning: A Whole Person Approach for Education. Apple River, Illinois: Apple River Press. 
Dunkel, Patricia A. (1986). Developing listening fluency in L2: Theoretical principles and pedagogical considerations. The Modern Language Journal, 70(2), 99-106.

Dunkel, Patricia A. \& F. Pialorsi. (1982). Advanced Listening Comprehension: Developing aural and note taking skills. Rowley, Massachusetts: Newbury House Publishing Co.

Gadamer, Hans Georg. (1976). Philosophical Hermeneutics. Translated \& edited by David E. Linge. Berkeley: University of California Press.

Glynn, S.M., \& L.D. Hartzell. (1978). Children's retention of topical and factual information following oral report activities. Paper presented at the annual convention of the Southeastern Psychological Association. Atlanta, Georgia. (ERIC Document Reproduction Service No. ED 158 207).

Goss, Blaine. (1982). Listening as information processing. Communication Quarterly, 30(4), 304-307.

Habermas, J. (1972). Review Symposium on Habermas. Philosophy of Social Sciences 2 .

Heidegger, M. (1961). Introduction to Metaphysics. New York: DoubledayAnchor.

Johnson, John R. (1984). The role of inner speech in human communication. Communication Education, 33, 211-222.

Kisslinger, Ellen, \& Michael Rost. (1980). Listening Focus: Comprehension Practice for Students of English. Tucson, Arizona: Lingual House Publishing.

Lebauer, R.S. (1988). Learn to Listen; Listen to Learn. Prentice-Hall.

Long, M.H., \& P.A. Porter. (1985). Group work, interlanguage talk, and second language acquisition. TESOL Quarterly, 19(2), 207-228.

Luria, A.R. (1969). Speech development and the formulation of mental processes. In Michael Cole \& Irving Maltzman, (Eds.) Handbook of Contemporary Soviet Psychology. New York: Basic Books.

Matthews, D. (1982). Teaching selective listening strategies for comprehension and acquisition. Paper presented at the 1982 National TESOL Convention, Honolulu, Hawaii. (ERIC Document Reproduction Service No. ED 222 090).

McCarthy, T. (1978). The Critical Theory of Jurgen Habermas. Cambridge, Massachusetts: The MIT Press.

Mendelsohn, D.J. (1984). There are strategies for listening. TEAL Occasional Papers, 8, 63-76.

Milk, R.D. (1985). The changing role of ESL in bilingual education. TESOL Quarterly, 19(4), 657-672.

Murphy, J.M. (1987). The listening strategies of English as a second language college students. Research \& Teaching in Developmental Education. 4(1), 2746. 
Nagle, S., \& S. Sanders. (1986). Comprehension theory and second language pedagogy. TESOL Quarterly, 20(1), 9-26.

O'Malley, J.M., A.U. Chamot, \& L. Kupper. (1987). Listening comprehension strategies in second language acquisition. Manuscript submitted for publication.

Ochsner, R. (1979). A poetics of second language acquisition. Language Learning, 29(1), 53-80.

Palmer, R.E. (1969). Hermeneutics: Interpretation theory. In Schleiermacher, Dilthey, Heidegger, and Gadamer. Evanston: Northwestern University Press.

Piaget, J. (1955). The Language and Thought of a Child. New York: New American Library.

Rardin, J. \& R. Oprandy. (1985). Listening skills through an 'understanding' relationship. TESOL Newsletter. 19(6).

Richards, J. (1980). Conversation. TESOL Quarterly, 14 (4), 413-432.

Ricoeur, P. (1981). Phenomenology and hermeneutics. In John B. Thompson (Ed. \& translator), Hermeneutics and the Human Sciences. Cambridge: Cambridge University Press.

Ross, S.M., \& F.J. Divesta. (1976). Oral summary as a review strategy for enhancing recall of textual material. Journal of Educational Psychology. 28, 689-695.

Rubin, R. \& C.V. Roberts, (1987). A comparative examination and analysis of three listening tests. Communication Education, 36, 142-153.

Ruetten, Mary K. (1986). Comprehending Academic Lectures: Instructor's Manual. New York: Macmillan.

Sims, J. \& P.W. Peterson. (1981). Better Listening Skills. Englewood Cliffs, N.J.: Prentice-Hall, Inc.

Sokolov, A.N. (1972). Inner Speech and Thought. New York.: Plenum Press.

Stevick, E.W. (1980). A Way and Ways. Rowley, Mass.: Newbury House Publishers.

Stewart, J. (1983). Interpretive listening: An alternative to empathy. Communication Education, 32(October), 379-391.

Streff, C.R. (1984). The concept of inner speech and its implications for an integrated language arts curriculum. Communication Education, 33(July), 223-230.

Vygotsky, L.S. (1962). Thought and Language. Cambridge, Mass.: The MIT Press.

Weinsheimer, J.C. (1985). Gadamer's Hermeneutics: A Reading of Truth and Method. New Haven: Yale University Press.

Wipf, J.A. (1984). Strategies for teaching second language listening comprehension. Foreign Language Annals, 17(4), 345-348. 
Wolff, F.I., N.C. Marsnik, W.S. Tacey, \& R.G. Nichols. (1983). Perceptive Listening. NewYork: Holt, Rinehart \& Winston.

Wolfin, A., \& C. Coakley. (1982). Listening (2nd Edition). Dubuque, Iowa: Brown Publishers.

Young, L. \& B. Fitzgerald. (1982). Listening and Learning Lectures. Rowley, Mass.: Newbury House Publishers.

\section{THE AUTHOR}

John M. Murphy prepares teachers in the Department of Applied Linguistics and ESL at Georgia State University. John previously has published in the TESOL Newsletter (1985) and in Research and Teaching in Developmental Education (1987). He currently is writing on the integration of speaking, pronunciation, and listening within ESL courses of oral communication. 